\title{
The impact of technological changes on income inequality: the EU states case study
}

\author{
Ganna Kharlamova \\ Department of Economic Cybernetics, \\ Taras Shevchenko National University of Kyiv \\ Ukraine \\ akbarlamova@ukr.net
}

\author{
Andriy Stavytskyy \\ Department of Economic Cybernetics, \\ Taras Shevchenko National University of Kyiv \\ Ukraine \\ a.stavytskyy@gmail.com
}

\section{Grigoris Zarotiadis}

Aristotle University of Thessaloniki

Greece

gzarotia@econ.auth.gr

Abstract. In spite of economic growth, which led to the creation of millions of new jobs, income inequality has been growing sharply in most parts of the world. There is no doubt that inequality of income is the single greatest threat to social stability throughout the world. Development of technologies contributes to the increase of labour productivity, replacement of job positions by robots and automatic machines, which can further exacerbate social inequality. The aim of this paper is to determine how changes in technology affect the inequality of income in European countries. Based on the econometric apparatus, two periods are investigated: the first one, from 2006 to 2017 and the second one, from 2010 to 2017, that characterizes a new economic era after the global financial crisis. All countries were clustered, which made it possible to generalize their social and technological development. The novelty is that we considered the dichotomy and cointegration of two economic categories - income inequality and technological changes. Using a model that features biased heterogeneity, factor proportions, and labour market frictions, we obtained four quite sufficient results. (1) Central European countries and the UK have reached such a level of development and redistribution in the economy that a change in labour productivity is not significantly associated with any deepening of inequality in incomes. (2) Periphery countries, due to their significant dependence on larger economies and lack of 
the developed mechanism for redistribution in the economy, are affected by technological changes. (3) The more economically developed is a country, the less impact on income inequality can be initialized by technological change. (4) The deeper is income inequality in a country, the more it responds to technological changes, but the impact on inequality can be both positive and negative.

Keywords: technology, income inequality, EU, cluster analysis, model.

JEL Classification: O11, O33, O52

\section{INTRODUCTION}

The long-lasting scientific and political discussion about the socioeconomic inequality has reached two major theoretic suppositions. In order to proceed further with a constructive analysis of the issue we need to restate that first, income and wealth disparities are not a subject of coincidence. Quite opposite to the liberal growth-theorists, who dogmatically support the illusion of convergence, it is rather the deeper systemic logic of the contemporary socioeconomic framework itself that provokes worsening of inequality as the result of its driving force: the continuously intensified competition of the (over-)centralized, economically active capitals.

Second, inequality goes beyond fairness. Having more income and wealth as compared to the rest of the society may be justified or not. After all, always this issue highly refers to the ethics of each epoch. The actual thing with inequality goes beyond that and has to do with the functionality of the contemporary socioeconomic reality. In capitalism, commodities are the functional cornerstones. Yet, in order for the commodities to cope with their role in sustaining the essential capitalist cycle, they have to be first produced and then $t$ sold. Inequality comes in the second step: the more uneven is the distribution of income, the shorter falls aggregate demand as compared to the total labour productivity. This leads to the reappearing of the vicious cycle of overproduction and overaccumulation of capital.

If reducing inequality should be understood as a method for preventing and or counteracting systemic crises, rather than an ethical issue, this speaks for the necessity of focusing on relative (rather than absolute) poverty and inequality measures and justifies the respective emphasis of the OECD (Veggeland, 2017). Atkinson and Brandolini (2004) provide a useful discussion on the meaning of dealing with absolute or relative inequality and they provide us with a historical overview of the respective developments since the 1980s. Asada (2010), although he focuses on inequality with respect to health services, states that choosing between absolute and relative inequality measures goes beyond the normative significance of inequality; above of the moral assessment of values, it refers also to technical understanding of inequality measures. In contrast to the studies that focus only in developing economies, the "growing unequal" thesis of the Organization1 stresses out the fact that since the contemporary growth goes along with a deepening of inequality globally, socially sustainability is not guaranteed. Brückner, Dabla-Norris and Gradstein (2014) argue that increases in national income have a significant moderating effect on income inequality: a one

${ }^{1}$ Starting from the relevant report in 2008 ("Growing Unequal? Income Distribution and Poverty in OECD Countries"), OECD was arguing that the gap between the rich and the poor in most OECD countries has widened over the past decades and that governments can close the gap with effective social policies. Seven years later the Organization kept on "ringing the bell": in the 2015 report the title was "In It Together: Why Less Inequality Benefits All", emphasizing exactly the systemic risks that result from the deepening convergence. 
percent increase in real GDP per capita, on average, reduces the Gini coefficient by around 0.08 percentage points.

The debate in contemporary literature reproduces the old theoretical dilemma: is inequality a motivation for growth or is it the (unacceptable) result of it? In this paper, we first rephrase this question substituting "labour productivity increases" (in other words - technological evolution) instead of "growth". Secondly, having in mind that causality may run in both directions depending on the development status of an economy, our intention is to couple with this question by investigating the older members of the EU aside to the new incomers, Central and Eastern European countries (CEEC). As we will deal with the economies that share common exogenous conditions for more than two decades, our empirical results will be more robust, efficiently contributing to the present-day debate.

A major issue that we deal with is the choice of reasonable, unbiased measurements and proxies, especially with respect to technological change and/or labour productivity. In the following, second section we present our database and methods that will be used in the econometric analysis presented in the third section. Lastly, we proceed with discussion and concluding remarks.

\section{LITERATURE REVIEW}

Technological change is "the engine of growth". Even more, the continuously intensifying rate of technological evolution is the second main characteristic of our time, next to the insisting stagnation of production and the explosive hoarding of (financial) capital (Andersson, 2017; Zygmunt, 2017). Therefore, as this has been already widely discussed in the relevant literature, searching for links between inequality and technology is quite inspiring. It is a challenge that we also choose to confront.

Technology opens the prospects for our well-being: it strengthens automation, generates extra possibilities for producing new products and services, reduces transportation costs, and enhances the efficiency of information management and communication. Overall, it increases the productivity of labour, directly or not, leading at the same time to the opening of new markets, spatially and in terms of product differentiation. Increased productivity and intensified labour sharing facilitated by the intensification of international trade widens the opportunities for personal and social progress. On the one hand, people involved in the globalized economy may become more successful, richer and educated Vveinhardt \& Kuklyte (2016). On the other hand, technological progress and the development of artificial intellect and robots increase exponentially labour productivity and provoke an exaggerated decline of labour intensity worldwide. The most dramatic changes will be met by poorly skilled workers, as their contribution can be easily replaced by automated lines, therefore, their income won't be even stable. The setting and adjustment processes will be provided mainly by highly qualified persons, who can earn even more comparing to present time. According to The Verge, only in the UK more than 350,000 paralegals, payroll managers, and bookkeepers could lose their jobs if automated systems can do the same work. Similar processes in other countries increase the inequality due to further automation.

Such changes lead to dramatic stratification in the society (for example Simionescu et al., 2017). Zarotiadis and Gkagka (2013) revealed the continuous path of divergence among the countries and among the classes in the European Union (EU) since the 1980s (Androniceanu, \& Ohanyan, 2016). According to the Eurostat, in 2012 a quarter of population or almost $125 \mathrm{mln}$ people in the EU were at risk of poverty. This ratio increases each year, it was $24.3 \%$ in 2011 and $23.7 \%$ in 2008. The gap between the wealthy and everyone else is much bigger in the USA. For example, in 2010, the richest 1 percent of American population had 34 percent of the accumulated wealth; the top 0.1 percent had some 15 percent. In 2012, the top 10 percent accounts for 48 percent of national income; the top 1 percent makes almost 20 percent and the top 0.1 makes nearly 9 percent. The disparity is rather big and in many cases can be explained by technological 
issues. For example, in the IT sphere the median income reached $\$ 94,000$ in 2013 , far above the national median of around $\$ 53,000$ (according to the Technology Review).

Nováková, Šoltés (2016) researched the quality of life, namely, the dimension of material living conditions in the Visegrad Group countries (hereinafter V4 countries) represented by Czech Republic, Hungary, Poland and Slovakia. They concluded that Czech Republic has the best position as compared to the rest V4 countries (exhibiting the best values in all the indicators except for the one representing housing conditions), Slovakia maintained the second position during the whole analysed period, Hungary recorded worsening almost in all the indicators and Poland improved its position mainly due to significant growth of income and decrease of the indicators representing material deprivation and poverty. Yet, the authors succeeded in assessing the income inequality only after developing the most adequate - integrated indices.

Studies carried out in the past 10 years have revealed that high level of inequality prevents economic growth (Pernica, 2017). Nevertheless, as stated by (Rakauskienè \& Volodzkiené, 2017), in order to study the actual level of socioeconomic inequality, we need to consider the distribution of wealth in different aspects. For this reason, they analysed the distribution of material living conditions and housing inequality in Lithuania and other EU countries, with a special focus on the extent and volatility of the problem. The authors concluded that the lack of high-quality housing, the housing cost overburden rate for a household, overcrowding in households and insufficient dwelling space are among the main issues faced by both Lithuanians and citizens of other EU member states. If this basic essential demand for satisfactory housing and a good living environment is not met, good quality of life could not be ensured.

Ostry, Berg and Tsangarides (2014); and Sanusi, Meyer and Slusarczyk (2017) stressed that different policies of income redistribution taken by governments do not disaffect economic growth, which means there is no excuse for inaction in a highly disparate environment. Fiscal policy has to play an important role in reducing income inequality. The most popular actions include different pensions and social security benefits, transfers and subsidies, progressive taxes, taxes for inheritance. Such tools may reduce inequality (measured by the Gini coefficient) on average by about a third in advanced economies (according the IMF). Moreover, Mincer (1958), Becker and Chiswick (1966) believed there is an unambiguously positive association between education and income inequality. A more recent research by Rajan (2015) notes that quality education is unreachable for many in the middle class and therefore prosperity of this class will suffer, increasing the inequality. Therefore, besides the corrective policy interventions, educational reforms count as a major preventive measure in contemporary societies.

On the opposite, other analysts argue that, especially in developing economies, policy interventions and the respective mechanisms for redistributing income usually lead to restriction of incomes of the most active part of the society, provoking the broadening of black economy, tax avoidance, migration of the most clever and enterprising people to more liberal or richer countries. Supporters of this view believe that, in this case, technological progress may suffer dramatically, generating thereby a reverse causality Ragulina et al., (2018). Dabla-Norris et al. (2015) argue that there is no common, universal solution for all countries. They empirically back their thesis that the drivers of inequality and their impact differ across the countries for different income groups. This results in different policy implications of cautiously chosen measures that deal with very specific inadequacies with respect to income allocation.

\section{METHODOLOGY}

\subsection{Data selection}

The structure of economic growth changed dramatically over past 35 years. According to Ministry of External Affairs of India share of world growth of emerging countries increased from 31\% in 1982-1987 to 
$74 \%$ in 2012-2017. For example, the USA contribution to the world economic growth decreased from $29.8 \%$ to $13.9 \%$ for the investigated period. At the same time, China's share increased from $9.9 \%$ to $33.6 \%$. If in the early 1980s eight countries had the share over 3\%, then nowadays only three countries have the bigger share: China, USA and India. This finding suggests that inequality in economic growth slightly but permanently decreases over time.

It should be added that technology level is still rather different from economic growth. According to technology index (Global Competitiveness Report), high positions occupied by developed countries including the USA, while China and India are located around 60th places. It means that despite the development of producing goods and services, technologically advanced countries will play an important role in providing the possibility for further non-extensive growth.

We can formulate a question whether economic growth and technology advances lead to real improvement of a human being. It is not a secret that in case of new technology development firstly a very restricted amount of persons can benefit. The same situation with economic growth. Economic growth and technology advances may lead to increasing inequality in countries. Therefore, an important part of the study is the formulation of clear hypotheses for testing.

Hypothesis 1. The development of technology negatively affects the system's ability to distribute income equitably.

Hypothesis 2. After the global financial crisis, technological development has accelerated the growth of income inequality.

The following data were selected for analysis:

1. The level of the Gini coefficient representing the degree of inequality in the country. It is a measure of statistical dispersion intended to represent the income or wealth distribution of a nation's residents, helps to make cross-country comparisons and is the most commonly used measure of inequality. A Gini coefficient of zero expresses perfect equality (for example, where everyone has the same income), while a value of 1 (or 100\%) expresses maximal inequality (e.g. only one person has all the income and all others have none).

2. The level of productivity, which is a proxy for the macroeconomic degree of technological change in the country. Of course, the development of technology cannot be directly related to the change in labour efficiency; most innovations generally have an indirect effect or will be displayed only after some time in the future (Lazányi, 2017). However, this indicator refers to the level of implementation of technological changes in the real economy. It should also be noted that labour productivity in some cases might not be related to technological changes because of significant changes in the economy or the presence of crises. However, from our point of view, this indicator is still the best proxy variable for the needs of our research.

All indicators are taken from Eurostat. Unfortunately, some of the observations were not in the sample, so the data were truncated for some countries. In particular, the initial data for Croatia, Romania and Switzerland date back to 2007, the final data for Ireland - to 2009. Thus, for these countries, the sample is appropriately limited.

To bring the data to one format, the Gini coefficient was transferred to the index, where the 2010 level was taken as one. Due to the peculiarities of construction and selection of data, it is not necessary to check them for stationarity. Numerical characteristics of data are presented in Tables 1 and 2.

Moving on with the stylized facts of our database, with respect to the Gini coefficient, income inequality in European countries is in general steadily increasing. From 2004 to 2016, the average indicator of income inequality has grown by almost 1 point from 29.12 to 30.06 , which makes a $3.2 \%$ increase. This trend differs among the countries. Bulgaria is allocated significantly aside: Gini coefficient here rose more than 7 points reaching a coefficient of inequality up to 38 points (more than $22 \%$ increase). Inequality also 
deepened in Sweden (+3.6), Cyprus (+3.3), Luxembourg (+3.2), Germany (+2.7), Spain (+2.6), France $(+2.0)$, Lithuania (+2.0), Austria (+1.9), Italy $(+0.8)$, Denmark (+4.0), Malta $(+1.4)$, Slovenia $(+0.7))$ and the Netherlands $(+0.5)$. In Greece, Gini coefficient has not changed, while in some countries it even dropped from -0.2 in the Czech Republic to -5.1 in Hungary.

Looking at the structure of our sample, in most countries the position with respect to the average European level has not changed significantly. This was majorly the case for those countries with relatively low-income inequality. In particular, Slovakia, Norway and Belgium began to live comparably more evenly. The greatest progress has been made by Hungary, which over the past 10 years was able to move from the group of countries with deeper disparities to one of the countries with a Gini coefficient below the European level.

On the other hand, the index of labour productivity in European countries as a whole rose from 95.36 in 2005 to 106.87 in 2016, which makes an overall growth of $12 \%$ (or about $1 \%$ per year on average). The largest gains in labour productivity were observed in Ireland $(+37.8 \%)$, Romania $(+27.9 \%)$, Bulgaria (+ $16.8 \%)$, Latvia $(+15.6 \%)$ and Lithuania $(+12.8 \%)$, the countries of Eastern Europe and the Baltics, as well as the well-known offshore "paradise" Ireland. We observe a worsening of labour productivity only in three countries: Greece $(-5.9 \%)$, Italy $(-2.1 \%)$ and Switzerland $(-0.9 \%)$. In the first two, this relates to an increase in unemployment due to significant economic shocks, while in Switzerland it results out of deflationary pressures induced by the applied monetary policy.

\subsection{Cluster analysis methodology}

Next, to the descriptive review, we proceed with an inferential assessment by applying a cluster analysis that categorises countries according to the above-described indicators of inequality and labour productivity, intending to consider their dissimilarities. For this purpose, we operate the program for data analysis Deductor (Kohonen maps for analysis as a good visualization tool). Cluster analysis includes methods that are adequate for a given set of data. The task of cluster analysis is to select groups in a given (learning) set of elements (by iterative fusion of the closest clusters). It allows grouping data around several centres in $\mathrm{n}$ dimensional space. Cluster analysis has a significant advantage over other methods of grouping objects as it is based on a fairly powerful formal mathematical apparatus, providing uniqueness in the distribution of objects with relative ease of use.

There are two main variants for making cluster analysis of time series: translate this data into a point data (which is easier) or analyse it as a time series. The result of the built-in self-organizing Kohonen map is the topological maps of the input signals, in which the spatial position of the lattice neurons is an indicator of the statistical significance of the input signals. The use of Kohonen self-organizing maps allows the following analytical operations to be carried out in the process of studying multidimensional objects:

- detect hidden (a priori unknown) structure of multidimensional data sets using clusters;

- describe the discovered clusters at the content level in terms of the distribution of the values of the attributes;

- determine whether an object belongs to a specific cluster;

- compare the positions on the map that occupy the objects, while assessing the degree of their differences;

- sort objects by complex criteria by selecting the appropriate zones on the map.

The algorithm of Kohonen self-organizing maps determines the mapping of the input array of country indicators $\mathbf{x}=\left[x_{1}, x_{2}, \ldots, x_{n}\right]^{T} \in X \subset \mathfrak{R}^{n}$ to a two-dimensional array of neuron arrays, where $X$ - the set of all possible indicators of the country; $\mathfrak{R}^{n}$ - the set of real numbers. 
There are two alternative variants of network typology: rectangular and hexagonal (Fig. 1). For the visual perception of the results, the hexagonal grid predominates since it does not have overwhelming horizontal and vertical directions in contrast to a rectangular one. This is explained by the following:

- the hexagonal grid has a lower spread to the centre of the topological map in comparison with the rectangular, with the same area;

- the distance between the centres of the two neurons is shorter;

- the distance between the neuron to the neighbouring neurons is always the same.
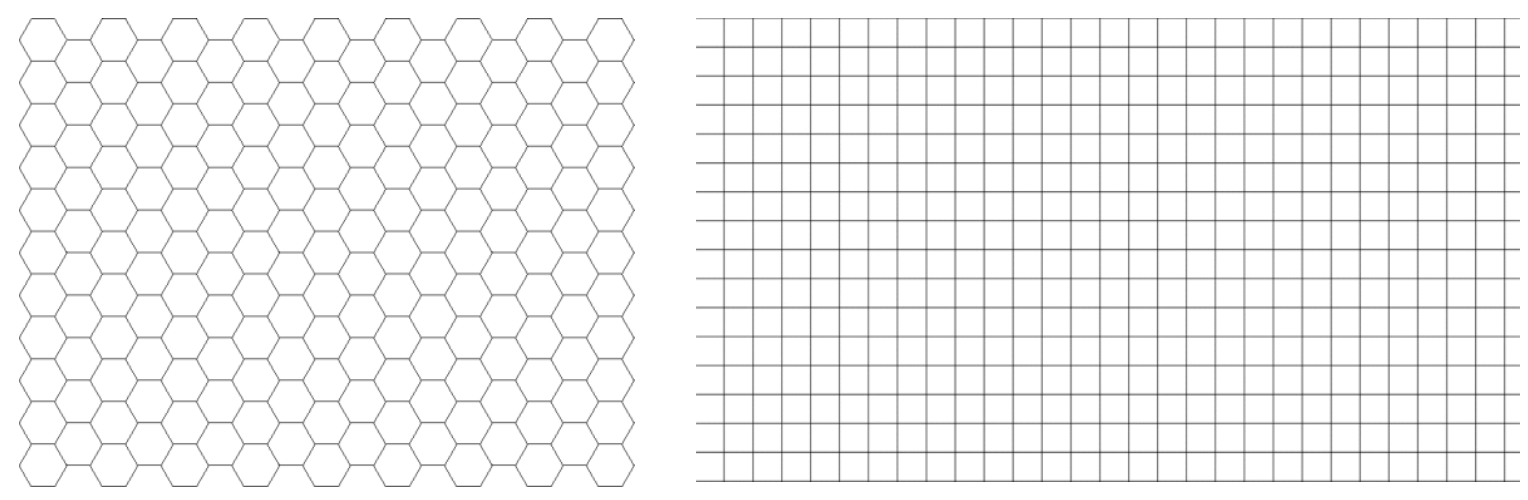

Figure 1. An example of a hexagonal (left) and rectangular (right) grid of neuronal selforganizing maps

Source: Kohonen \& Teuvo (1982).

In addition to the form of neurons, one of the fundamental tasks of constructing self-organizing maps is to determine the number of neurons. T. Kohonen (2001) noted that the optimal number of neurons is determined by the problem to be solved by the neural network.

At the stage of building a self-organizing map for the countries, the dimension of a self-organizing map is proposed to be selected experimentally, from a number of variants according to the criterion of the weighted average quantization error. The quantization error matrix represents the average distance between the sample and the centre of the cells (which correspond to the nodes of the Kohonen map grid). Each example is displayed in a multidimensional space, where the number of measurements corresponds to the number of input indicators (elements of the vector of input data). The centre of the cell is the point in this space with coordinates equal to the weights of the neuron. The smaller the distance from the vector of input data to the centre of the cell, the closer to it is an example, which is described by this vector.

In addition, in the process of building of a self-organizing map, on the recommendation of T. Kohonen, it is necessary to obtain information on the nature of structures and the distribution of input data. To identify topological relationships between elements of a data collection, it is always advisable to conduct a preliminary analysis using, for example, some nonlinear projection methods. T. Kohonen focuses on the possibility of linear initialization, which, under certain conditions, allows narrowing the neighbourhood function and reducing the value of the learning speed coefficient.

Numerous researchers had shown that the algorithm for constructing self-organizing maps allows different variants of choosing the neighbourhood function and the speed of learning. However, the most worthy are the following:

- the neighbourhood function should be broad enough at the beginning of and be reduced during the learning process so that at the end of this process only the immediate neighbours of the winning neuron are influenced; 
- $\quad$ the process of self-organization should include a fairly large number of training iterations.

At the final stage of the building of a self-organizing map, there is a process of synaptic adaptation. The result of the constructed self-organizing map is the visual representation of a two-dimensional hexagonal grid of neurons reflecting the organizational dependence of the countries on Gini coefficients with the possibility of a further definition of clusters, which are similar in terms of economic development and conditions (Fig. 2).

At the final stage of calculations, at the second level of the hierarchy, the location of the main research country and the cluster to which it belongs is determined. This procedure is carried out by entering the vector of the country's indicators $\mathbf{x}^{*}=\left[x_{1}{ }^{*}, x_{2}{ }^{*}, \ldots, x_{n}^{*}\right]^{T}$ at the input of the constructed Kohonen selforganizing map. The model determines the country's location on the hexagonal grid of the neurons and returns the coordinates of the neuron and the cluster number to which the country belongs. This allows us to determine the circle of countries in the world that are similar in terms of the Gini coefficients and to assert that the country's assessment should be performed based on the corresponding cluster of countries.

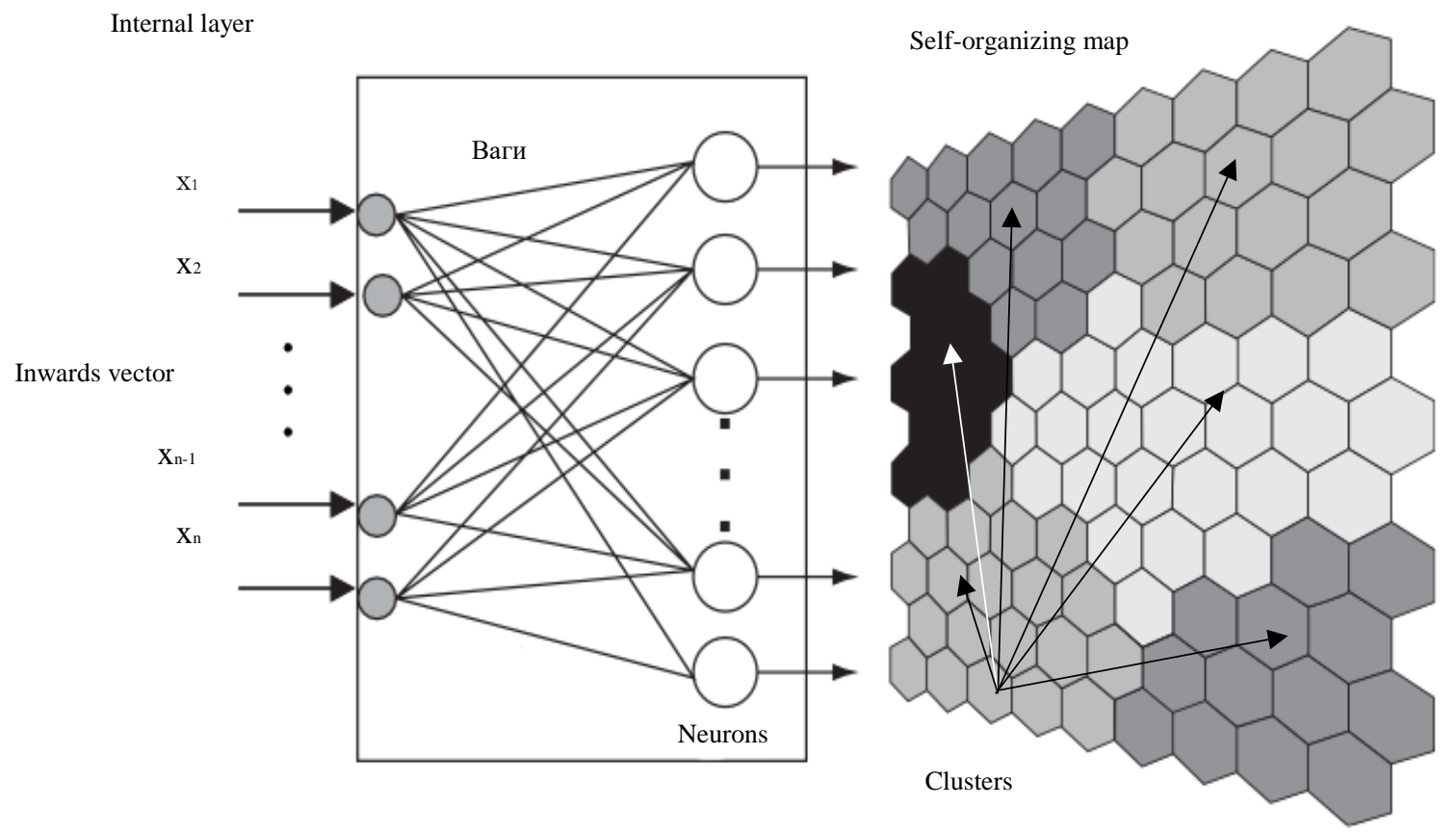

Figure 2. Visual representation of a self-organizing map with the definition of clusters Source: Gorban, et al (Eds.) (2008)

\section{EMPIRICAL ANALYSIS OF TECHNOLOGICAL CHANGES IMPACT ON INCOME INEQUALITY AND DISCUSSION}

\subsection{Cluster analysis of countries by Gini coefficient}

Based on the above-described methodology, we proceeded with the cluster analysis for European countries. In all calculations, we used 95\% level of confidence to adjust specific regions (fig.3). 


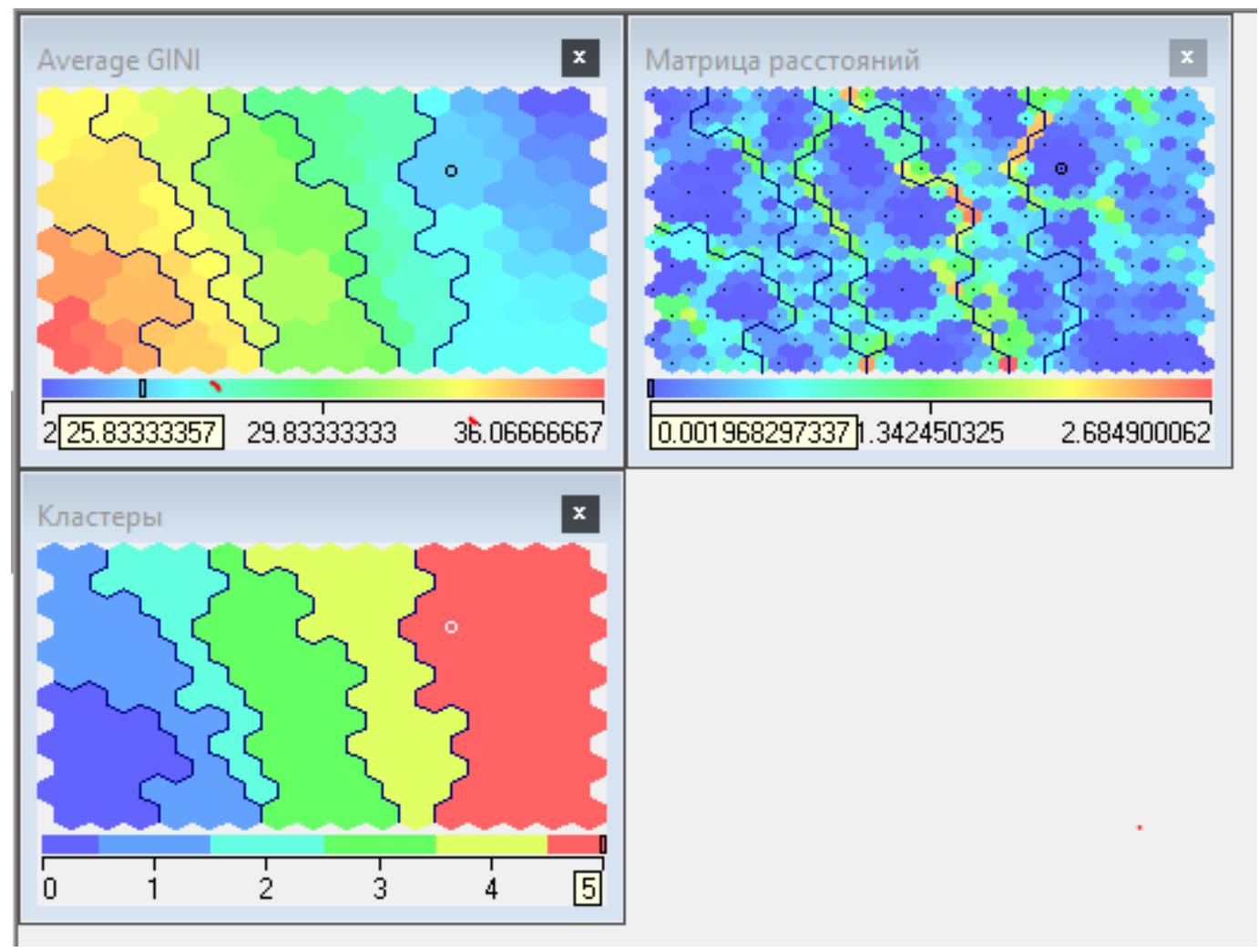

Figure 3. Kohonen's maps

Source: calculated by authors

At the end, we have six different clusters, as shown by the percent of similarity of different clusters in the following matrix of comparison (fig. 4).

\begin{tabular}{|r|r|r|r|r|r|r|}
\hline 5 & \multicolumn{1}{|c|}{0} & \multicolumn{1}{c|}{1} & \multicolumn{1}{c|}{2} & \multicolumn{1}{c|}{3} & \multicolumn{1}{c|}{4} & \multicolumn{1}{c|}{5} \\
\hline 0 & $100.00 \%$ & $81.77 \%$ & $70.83 \%$ & $54.57 \%$ & $27.65 \%$ & $0.00 \%$ \\
\hline 1 & $81.77 \%$ & $100.00 \%$ & $89.06 \%$ & $72.80 \%$ & $45.88 \%$ & $18.23 \%$ \\
\hline 2 & $70.83 \%$ & $89.06 \%$ & $100.00 \%$ & $83.73 \%$ & $56.82 \%$ & $29.17 \%$ \\
\hline 3 & $54.57 \%$ & $72.80 \%$ & $83.73 \%$ & $100.00 \%$ & $73.09 \%$ & $45.43 \%$ \\
\hline 4 & $27.65 \%$ & $45.88 \%$ & $56.82 \%$ & $73.09 \%$ & $100.00 \%$ & $72.35 \%$ \\
\hline 5 & $0.00 \%$ & $18.23 \%$ & $29.17 \%$ & $45.43 \%$ & $72.35 \%$ & $100.00 \%$ \\
\hline
\end{tabular}

Figure 4. Matrix of comparison

Source: calculated by authors

Proceeding with the analysis of our clusters (see the column of method 1 in table 3), we can see that there are three countries in the cluster 0 with Gini coefficient higher than 34\%, meaning the highest level of income differentiation among the population of these countries. The next cluster contains countries with less pronounced diversification (Gini coefficient from 33.5\% to 33\%). Countries with the lowest level of income inequality are in the cluster 5 (Gini coefficient is less than 27\%). 
Clustering of countries based on Gini index

\begin{tabular}{|c|c|c|c|}
\hline Country & Average Gini & Cluster (method 1) & Cluster (method 2) \\
\hline Austria & 26.83 & 5 & 3 \\
\hline Belgium & 26.81 & 5 & 3 \\
\hline Bulgaria & 33.52 & 1 & 1 \\
\hline Croatia & 30.71 & 3 & 0 \\
\hline Cyprus & 30.75 & 3 & 2 \\
\hline Czech Republic & 25.09 & 5 & 3 \\
\hline Denmark & 25.67 & 5 & 3 \\
\hline Estonia & 33.47 & 1 & 2 \\
\hline Finland & 25.83 & 5 & 3 \\
\hline France & 28.83 & 4 & 0 \\
\hline Germany & 28.78 & 4 & 0 \\
\hline Greece & 33.81 & 1 & 1 \\
\hline Hungary & 26.92 & 5 & 0 \\
\hline Ireland & 30.54 & 3 & 2 \\
\hline Italy & 32.06 & 2 & 2 \\
\hline Latvia & 36.07 & 0 & 1 \\
\hline Lithuania & 34.85 & 0 & 1 \\
\hline Luxembourg & 28.09 & 4 & 2 \\
\hline Malta & 27.58 & 4 & 0 \\
\hline Netherlands & 26.52 & 5 & 3 \\
\hline Norway & 24.73 & 5 & 3 \\
\hline Poland & 31.50 & 3 & 0 \\
\hline Romania & 34.28 & 0 & 1 \\
\hline Slovakia & 25.21 & 5 & 3 \\
\hline Slovenia & 23.60 & 5 & 3 \\
\hline Spain & 33.03 & 1 & 1 \\
\hline Sweden & 24.50 & 5 & 3 \\
\hline Switzerland & 29.73 & 3 & 0 \\
\hline The United Kingdom & 32.78 & 2 & 2 \\
\hline
\end{tabular}

Source: calculated by authors

Next, we wanted to apply cluster analysis by considering the time series. Therefore, we had filled the non-existing data by using linear trends for this. Thereby, we got a matrix with Gini coefficients for each country at every year from 2001 to 2016 (see fig. 5 and the corresponding matrix of comparison in fig. 6 shows the percentage of similarity of the different clusters). 


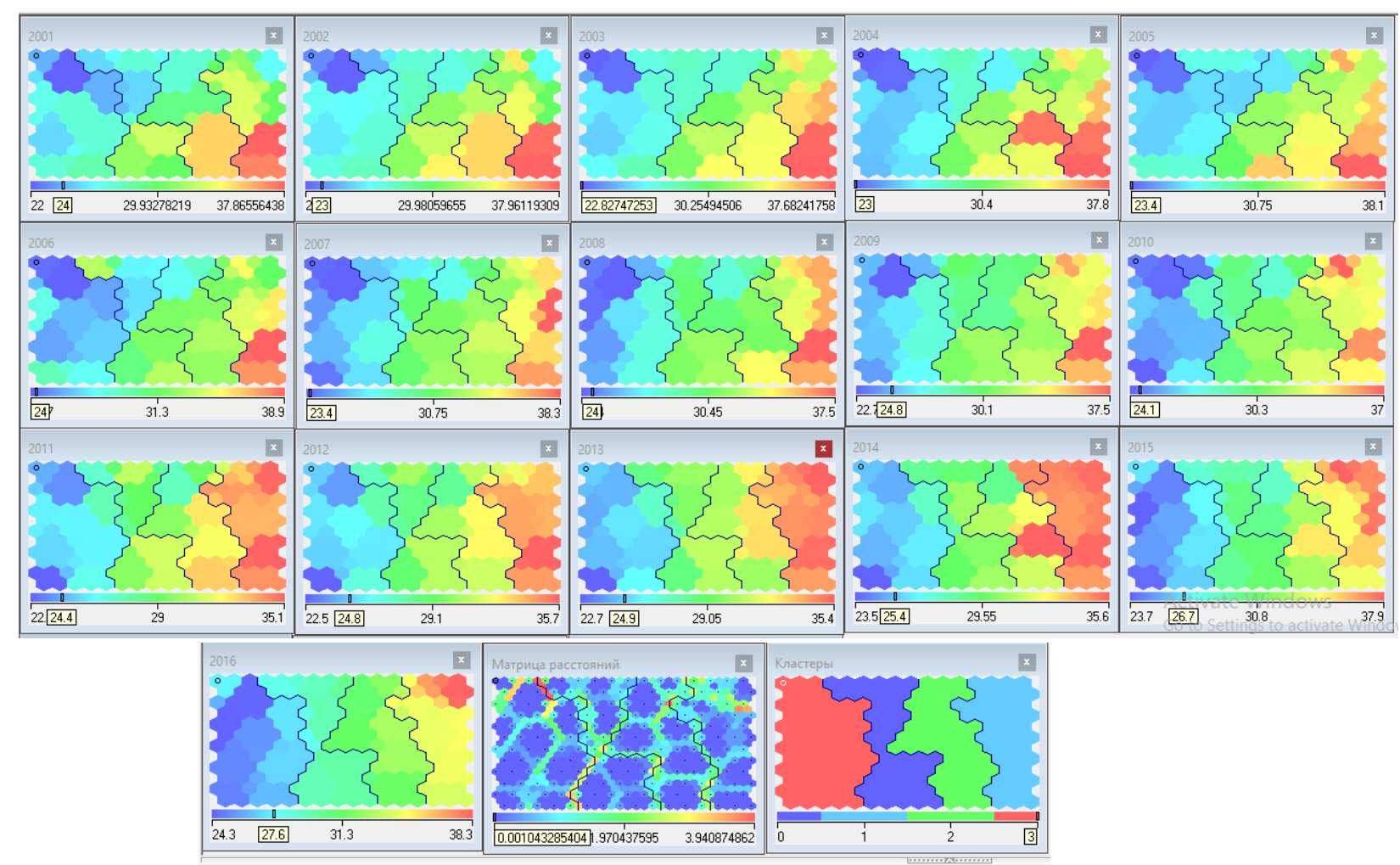

Figure 5. Clusters on the base of Gini coefficient with time series approach Source: calculated by authors

\begin{tabular}{r|c|r|r|r|}
\hline & \multicolumn{1}{c|}{0} & \multicolumn{1}{c|}{1} & \multicolumn{1}{c|}{2} & \multicolumn{1}{c|}{3} \\
\hline 0 & $100.00 \%$ & $37.70 \%$ & $73.26 \%$ & $62.17 \%$ \\
\hline 1 & $37.70 \%$ & $100.00 \%$ & $64.25 \%$ & $0.00 \%$ \\
\hline 2 & $73.26 \%$ & $64.25 \%$ & $100.00 \%$ & $35.69 \%$ \\
\hline 3 & $62.17 \%$ & $0.00 \%$ & $35.69 \%$ & $100.00 \%$ \\
\hline
\end{tabular}

Figure 6. Matrix of comparison

Source: calculated by authors

The structure of clusters is shown in table 3 as well (see the column of method 2). Although both methods provide similar results and the majority of countries are allocated to similar or neighbouring clusters, there are several exceptions - for instance, France, Germany, Hungary, Malta, Poland, Switzerland. Thus, it differs in these exceptions with Alonso et al (2016) but is in the synergy with the results of Mackenbach et al (2008).

\subsection{Regression analysis}

Given the considerable limitation of data for a longer time period, the analysis was carried out using a simple linear regression. It was decided not to build a panel regression due to the requirement to determine the impact of the labour productivity parameter for each country separately. These models are beneficial for expert discussions regarding the concept of Cobb-Douglas model and its analogies.

It was also decided to build regressions for two periods. The first covers 2006-2016 (for some countries 2007-2016). The second focuses on the situation after the global financial crisis, 2010-2016. 
The main model has the form:

$$
y_{t}=\beta_{0}+\beta_{1} x_{t}+\varepsilon_{t}, t=\overline{1, n}
$$

where $y_{t}$ is the level of income inequality in the period $t, x_{t}$ the level of labour productivity in the period $\mathrm{t}, \beta_{0}, \beta_{1}$ and $\varepsilon_{t}$ represents the regression coefficients and the residuals respectively and finally $\mathrm{n}$ is the number of observations.

Table 4

Model coefficient for European countries

\begin{tabular}{|c|c|c|c|c|}
\hline \multirow[b]{2}{*}{ Country } & \multicolumn{2}{|c|}{ 2006-2016 } & \multicolumn{2}{|c|}{ 2010-2016 } \\
\hline & $\beta_{1}$ & Prob & $\beta_{1}$ & Prob \\
\hline Belgium & -0.85 & 0.13 & -0.31 & 0.26 \\
\hline Bulgaria & 0.50 & 0.01 & 0.69 & 0.00 \\
\hline Czech Republic & -0.02 & 0.83 & 0.06 & 0.54 \\
\hline Denmark & 0.79 & 0.13 & 0.30 & 0.22 \\
\hline Germany & 0.60 & 0.33 & 0.36 & 0.39 \\
\hline Estonia & 0.65 & 0.04 & 0.74 & 0.06 \\
\hline Greece & -0.09 & 0.42 & -0.56 & 0.01 \\
\hline Spain & 0.71 & 0.00 & 0.63 & 0.00 \\
\hline France & 0.47 & 0.62 & -0.50 & 0.32 \\
\hline Croatia & -0.55 & 0.05 & -0.55 & 0.04 \\
\hline Italy & -0.40 & 0.09 & -0.38 & 0.46 \\
\hline Cyprus & 5.44 & 0.13 & 7.11 & 0.04 \\
\hline Latvia & -0.42 & 0.00 & -0.31 & 0.02 \\
\hline Lithuania & 0.07 & 0.72 & 0.01 & 0.97 \\
\hline Luxembourg & -0.37 & 0.38 & 0.43 & 0.64 \\
\hline Hungary & -0.51 & 0.87 & 3.92 & 0.13 \\
\hline Malta & 0.46 & 0.07 & 0.38 & 0.08 \\
\hline Netherland & 0.20 & 0.74 & 0.33 & 0.54 \\
\hline Austria & -0.84 & 0.37 & -0.70 & 0.32 \\
\hline Poland & -0.31 & 0.00 & -0.21 & 0.00 \\
\hline Portugal & -1.38 & 0.00 & -0.66 & 0.03 \\
\hline Romania & 0.23 & 0.09 & 0.23 & 0.09 \\
\hline Slovenia & 0.68 & 0.04 & 0.85 & 0.02 \\
\hline Slovakia & -0.38 & 0.11 & -0.25 & 0.37 \\
\hline Finland & 0.35 & 0.10 & -0.18 & 0.54 \\
\hline Sweden & 1.45 & 0.00 & 1.28 & 0.02 \\
\hline United Kingdom & -0.70 & 0.27 & -0.67 & 0.29 \\
\hline Norway & 2.85 & 0.04 & 1.38 & 0.12 \\
\hline Switzerland & 0.38 & 0.63 & -1.06 & 0.34 \\
\hline
\end{tabular}

Source: calculated by authors 
After the evaluation, the models were checked for the significance (in general and for the coefficients). Due to the small amount of data, it makes no sense to check the results for the presence of heteroscedasticity and autocorrelation since the relevant tests will show the false presence of these characteristics. However, the factor analyses and CUSUM - analyses let us to continue with this short time series, as the amount of observations is still higher that adjusted number of variables.

According to the above methodology, regressions have been estimated for most European countries. The complete results are summarized in Table 4.

As we see from Table 4, the impact of changes in labour productivity is significant only in certain countries. The most noteworthy point is that insignificant influence is observed in the relatively developed and large economies. In particular, this is the case in Germany and in all its neighbours, except Poland. In addition, the lack of dependence can be observed in Lithuania, Hungary and Slovakia. Thus, the methodology of next steps in the development of the topic we had risen should be in the application of panel data with fixed effects for receiving more mathematically grounded results. However, it could be possible only with the increasing of time series, or publishing the quarter date in open statistics sources on the EU.

On the other hand, in Bulgaria this relationship is strong enough and permanent. For example, with an increase in the index of productivity by $1 \%$, the index of inequality increases by $0.5-0.69 \%$. Even stronger is the relationship in Estonia (0.65-0.74), Spain (0.63-0.71), Slovenia (0.68-0.85) and Sweden (1.28-1.45). Significant effects can also be found in Malta (0.38-0.46), Romania (0.23) and Norway (1.38-2.85). Cyprus is a distinguished case, as the growth of inequality simply explodes with increasing productivity (impact from 5.44 to 7.11$)$.

On the contrary, there are countries for which we observe a completely different trend, where an increase in labour productivity by $1 \%$ leads to significant improvements of inequality: Croatia (-0.55), Italy (-0.4), Latvia (-0.31- -0.42), Poland (-0.21- -0.31), and Portugal (-0.66-1.38).

Next, we divide all countries into parts, depending on the sign of the corresponding coefficient of regression. To the first group we classify countries with a negative sign ( 0 -column), to the second countries with an insignificant coefficient (1-column), to the third the countries with a positive coefficient (2-column). Then we consider clustering according to the Gini coefficient, estimated and presented in table 3 (method1 column). Table 5 presents this combined categorization.

Table 5

Combination of different methods of clustering

\begin{tabular}{|c|c|c|c|}
\hline & \multicolumn{3}{|c|}{ Regression Clusters } \\
\hline $\begin{array}{c}\text { Gini } \\
\text { Clusters }\end{array}$ & 0 & 1 & 2 \\
\hline 0 & Latvia & Lithuania & Romania \\
\hline 1 & Greece & - & Bulgaria, Estonia, Spain \\
\hline 2 & Italy & The UK & Malta \\
\hline 3 & Croatia, Poland & France, Germany, Luxemburg & \\
\hline 4 & - & $\begin{array}{c}\text { Austria, Belgium, Czech Republic, } \\
\text { Denmark, Finland, Hungary, } \\
\text { Netherlands, Norway, Slovakia }\end{array}$ & Slovenia, Sweden \\
\hline 5 & - & .
\end{tabular}

Source: calculated by authors

As seen in table 5, the most developed countries in Europe, regardless of the current state of inequality, have opportunities to address problems that may result from the technological development (1-column). 
Moreover, countries with a relative low level of inequality of incomes (for instance Austria, Belgium, Czech Republic, Denmark, Finland, Hungary, Netherlands, Norway, and Slovakia and also France, Germany, and Luxemburg) will be able to keep it in the future as well, regardless the continuing technological progress. There are several exceptions. Slovenia and Sweden, although they belong to the countries with the lowest inequality of income, they suffer a deepening of inequality resulting from technological changes. In Sweden, this could be explained by the complexity of the transition from the extremely even distribution of incomes to more competitive one, while in Slovenia this may be due to the rapid development of industrial production. So far, such changes do not cause problems in these countries, but if the political course would be kept unchanged, there could be certain social inconveniences. A similar situation is observed in Malta, where, as a result of the rapid development of tourism, rather wealthy people began to appear, while in Cyprus inequality is also increasing probably due to the high level of offshore schemes.

In Switzerland, as well as in nearly every of Germany's neighbours, there is a high level of social sphere development, as a result of which the technological gains are not associated with any deterioration of inequality. Poland (another neighbour of Germany) and Croatia go even better as the inequality of income decreases along with the development of technology.

Another cluster is formed by Great Britain and Italy. These countries are rather similar in most of the indicators under consideration, but in Italy, there are opportunities to reduce inequality of incomes, and the UK is neutral to technology development.

A fairly interesting result is the cluster of countries with a high and extremely high level of inequality of the population. Among them only in Lithuania, we can speak about the neutrality of technological changes. In all other countries, either the development of technology leads to an increase in inequality (Bulgaria, Estonia, Spain and Romania), or a decrease (Latvia and Greece). (The case of these two countries needs to be examined more carefully.)

In general, we can draw the following conclusions from the above:

- the more economically developed the country is, the less likely it is for the technological change to have an adverse impact on income inequality;

- if the country has a high level of inequality of income, the more it responds to technological changes. Moreover, the impact can be both, positive and negative.

From the economic point of view, the results indicate that governments need to react sensibly to technological change. In particular, for countries located far from Germany, one should carefully analyze how technologies are implemented in the country and prevent them from the significant increasing in only a few industries. Since, it can increase distortions in the country. It should be highlighted that it is also very important to increase social benefits to non-working people in the case of a sharp increase in labor productivity. The absence of such a reaction can lead to social tensions in the country. Cyprus is a vivid example of what might happen to a country if investments in it are significantly increased, but the government would not be able to make decisions that could offset the negative effects. Due to the peculiarities of legislation, this country acts as an European offshore, stimulating the flow of investments. However, due to the fact that only a limited ratio of people actually enjoy the benefits of them, the income inequality has been substantially increased in the country. At the same time, in Germany and most of its neighbors, governments have significant reserves, which allow much more slowly implementing of social changes.

\section{CONCLUSION}

The ambition of this article was to contribute to the ongoing academic discussion with respect to the determinants of technological changes and their impact on domestic income inequality. The literature review 
showed that various indicators and methods have been applied to measure the relationship in question; therefore, we chose a combination of regression and cluster analysis as the most appropriate method to realize the objectives of this research. Our methodology was divided into five steps: after the determination of research objectives, we proceeded with a critical literature review and we defined the research hypotheses; the third step was the selection of the appropriate methods and data acquisition; next, we processed the data using the chosen mathematical and statistical instruments. In the last step, we interpreted the results and we verified the hypotheses.

Understanding the milestone of the regression application on short time periods, we can argue that this regression had shown stable and sufficient results on other states data. The limitation of our research was as well in the impossibility to be evident that there is the linear relationship without any lag between discusses variables. However, great shortage of time series length opens this niche of the research for the next investigation attempts.

Overall, income inequality deepens worldwide. The study in the previous pages showed that in Europe there is a trend to congregate the level of inequality in the different countries. Moreover, we saw that the larger the country, the less likely it is to experience a worsening of inequality in association with technological changes. In part, this can be explained by the fact that technological development slips into a certain part of the economy, which, in a large country, may be relatively small. At the same time, for small countries, such changes often become a catalyst for structural adjustments that strengthen disparities. Bright examples of this situation are Cyprus and Malta.

We also showed that only five countries in Europe (Latvia, Greece, Italy, Croatia, and Poland) offset the impact of technological change on inequality of the population, achieving a more fair distribution of income. On the contrary, eight countries suffer from increasing income inequality in the course of technological change. If in Slovenia and Sweden such changes are due to the procedure of adjusting domestic inequality to the average European level, in Cyprus and Malta the small size of the economy could be the explanation, while in Bulgaria, Estonia, Spain and especially in Romania the wrong economic policy is the main justification. The situation in Romania, in general, remains very complicated: despite the high level of inequality that exists, the penetration of new technologies leads to its further worsening, which means a significant deterioration of the social conditions for the population.

Summing up, we can now stress that the answer to our first hypothesis should be negative. In reality, technological changes induce a different impact on income inequality. This impact depends on the country's size, its level of development and the current degree of income inequality relative to the average European value. The same we obtain for the next hypothesis about accelerated inequality growth after world economic crisis: for the majority of the studied countries nothing changed with respect to the impact of technological changes on income inequality.

Overall, we can draw the following conclusions:

1. The countries of central Europe and the United Kingdom have reached such a level of development and redistribution in the economy that the rise of labour productivity does not have any significant adverse effects on income inequality.

2. Inequality in peripheral countries seems to be adversely affected by technological changes because of their significant dependence on larger economies and the lack of well-established mechanisms for redistribution in the economy.

3. In general, the greatest negative impact can be seen in Cyprus, where the increase in inequality, associated with the growth of labour productivity that primarily results from the flow of funds to the well-known offshore branches. Accordingly, the owners of such companies are mostly in benefits, which increases the inequality of incomes. 
4. From our point of view, the changes in Scandinavian countries (Norway and Sweden) should be treated differently. These countries did not manage yet to restore productivity growth after the financial crisis.

5. At the same time, the countries of southern Europe and Estonia are usually characterized by deepening inequalities associated with technological changes.

6. Finally, the next block of countries (Croatia, Italy, Latvia, and Poland) has an inverse relationship between labour productivity and technological changes. That can be explained by the fact that in those countries there was a rather high level of inequality initially, which in recent years has been decreasing due to the change of distribution mechanism in the countries. Portugal also confirms this view: Portuguese Ginny coefficient went back by nearly 4 points over the past decade, towards the European average levels.

7. The more economically developed a country is, the less impact on income inequality could be caused by technological changes.

8. If the country has a high level of inequality of income, the more it responds to technological changes. Yet, the impact can be both positive and negative.

\section{ACKNOWLEDGEMENT}

This work was supported by the scientific \& research faculty thematic (2016-2018): 16KF040-04 "Stable state security assessment: a new framework for analysis" (Taras Shevchenko National University of Kyiv, Ukraine).

\section{REFERENCES}

Alonso, D. B., Androniceanu, A., \& Georgescu, I. (2016). Sensitivity and vulnerability of European countries in time of crisis based on a new approach to data clustering and curvilinear analysis. Administratie si Management Public, (27), 46.

Andersson, M., \& Stone, T. A. (2017). Global sourcing and technical efficiency-a firm-level study on the ICT industry in Sweden. Journal of Business Economics and Management, 18(5), 877-896.

Androniceanu, A., \& Ohanyan, G. (2016). Comparative approach on education and healthcare in Romania and Bulgaria as beneficiaries of the IMF financial assistance. Administratie si Management Public, (26), 25-48.

Asada, Y. (2010). On the Choice of Absolute or Relative Inequality Measures. Milbank Quarterly, 88(4), 616-622. doi:10.1111/j.1468-0009.2010.00614.x

Atkinson A., \& Brandolini, A. (2004). Global World Inequality: absolute, relative or intermediate? Working paper. Retrieved from http://www.iariw.org/papers/2004/brand.pdf

Becker, G. S., and B. R. Chiswick. (1966). Education and the Distribution of Earnings. American Economic Review, 56, $(1 / 2), 358-69$.

Bruckner, M., Dabla-Norris, E., \& Gradstein, M. (2014). National Income and Its Distribution. IMF Working Papers, 14(101), 1. doi:10.5089/9781498347815.001

Dabla-Norris, M. E., Kochhar, M. K., Suphaphiphat, M. N., Ricka, M. F., \& Tsounta, E. (2015). Causes and consequences of income inequality: a global perspective. International Monetary Fund. Retrieved from https://www.imf.org/external/pubs/ft/sdn/2015/sdn1513.pdf

Eurostat. Retrieved from http://ec.europa.eu/eurostat/data/database

Eurostat. $\quad$ Retrieved from http://ec.europa.eu/eurostat/statisticsexplained/index.php/Being young in Europe today - living conditions.

Global Competitiveness Report 2004-2005. "Countries Compared by Economy > Technology index. International Statistics at NationMaster.com", World economic forum. Aggregates compiled by NationMaster. Retrieved from http://www.nationmaster.com/country-info/stats/Economy/Technology-index 
Gorban, A. N., Kégl, B., Wunsch, D. C., \& Zinovyev, A. Y. (Eds.). (2008). Principal manifolds for data visualization and dimension reduction (Vol. 58, pp. 96-130). Berlin-Heidelberg: Springer. Kohonen T. (2001) Self-Organizing Maps (Third Extended Edition), New York.

Kohonen, T. (1982). Self-Organized Formation of Topologically Correct Feature Maps. Biological Cybernetics, 43(1), 5969. doi: $10.1007 /$ bf00337288

Lazányi, K. (2017). Innovation - the role of trust. Serbian Journal of Management, 12(2), 331-344.

Mackenbach, J. P., Stirbu, I., Roskam, A. J. R., Schaap, M. M., Menvielle, G., Leinsalu, M., \& Kunst, A. E. (2008). Socioeconomic inequalities in health in 22 European countries. New England Journal of Medicine, 358(23), 24682481.

Mincer, J. (1958). Investment in Human Capital and Personal Income Distribution. Journal of Political Economy, 66(2), 281-302.

Ministry of External Affairs of India. Retrieved from http://mea.gov.in/articles-in-foreignmedia.htm?dtl/21810/Southeastern + shift + The + new + leaders + of + global + economic + growth

Nováková, B., \& Šoltés, V. (2016). Quality of Life Research: Material Living Conditions in the Visegrad Group Countries, Economics and Sociology, 9(1), 282-294. doi: 10.14254/2071-789X.2016/9-1/19

Ostry, J. D., Berg, A., \& Tsangarides, Ch. G. (2014) Redistribution, Inequality, and Growth. IMF Working Papers. Retrieved from https://www.imf.org/external/pubs/ft/sdn/2014/sdn1402.pdf

Pernica, M. (2017) The business impact analysis of the Minimum Wage valorisation. Business: Theory and Practice 18(1), 88-95.

Ragulina Y.V., Semenova E.I., Zueva I.A., Kletskova E.V., \& Belkina, E.N. (2018). Perspectives of solving the problems of regional development with the help of new Internet technologies. Entrepreneurship and Sustainability Issues, 5(4). doi:10.9770/jesi.2018.5.4(13)

Rajan, R.G. (2015). Democracy, Inclusion, and Prosperity. Speech at the D.D. Kosambi Ideas Festival Goa, India, February 20.

Rakauskienè, O. G., \& Volodzkienè, L. (2017). The Inequality of Material Living Conditions in EU Countries. Economics and Sociology, 10(1), 265-278. doi: 10.14254/2071-789X.2017/10-1/19.

Sanusi, K. A., Meyer, D., \& Ślusarczyk, B. (2017). The relationship between changes in inflation and financial development. Polish Journal of Management Studies, 16(2), 253-265. doi:10.17512/pjms.2017.16.2.22

Simionescu, M., Lazányi, K., Sopková, G., Dobeš, K., \& Adam, P. B. (2017). Determinants of economic growth in V4 countries and Romania. Journal of Competitiveness, 8(1), 103-116. doi:10.7441/joc.2017.01.07

The IMF. (2014). Retrieved from http://www.imf.org/external/np/pp/eng/2014/012314.pdf.

The Technology Review. Retrieved from https://www.technologyreview.com/s/531726/technology-and-inequality/

The Verge. Retrieved from https://www.theverge.com/2017/7/13/15963710/robots-ai-inequality-social-mobilitystudy.

Veggeland, N. (2017). Confrontation of economic politics. Economics, Management and Sustainability, 2(2), 56-61. doi:10.14254/jems.2017.2-2.6.

Vveinhardt, J., \& Kuklytè, J. (2016). Development Improvement Programme of Social Business Models in Lithuania. Forum Scientiae Oeconomia, 4(4), 149-170.

Zarotiadis, G., \& Gkagka, A. (2013). European Union: a diverging Union? Journal of Post Keynesian Economics, 35 (4), $537-$ 568. doi:10.2753/pke0160-3477350403.

Zygmunt, A. (2017). Innovation activities of Polish firms. Multivariate analysis of the moderate innovator countries. Oeconomia Copernicana, 8(4), 505-521. doi:10.24136/oc.v8i4.31. 


\section{APPENDIX}

Table 1

Gini Index Descriptive Statistics

\begin{tabular}{|c|c|c|c|c|c|c|c|}
\hline Country & Mean & Median & $\begin{array}{c}\text { Standard } \\
\text { Deviation }\end{array}$ & $\begin{array}{c}\text { Sample } \\
\text { Variance }\end{array}$ & Range & Minimum & Maximum \\
\hline Belgium & 100.46 & 99.06 & 2.95 & 8.69 & 9.02 & 97.37 & 106.39 \\
\hline Bulgaria & 105.07 & 106.33 & 5.61 & 31.47 & 21.39 & 93.98 & 115.36 \\
\hline $\begin{array}{l}\text { Czech } \\
\text { Republic }\end{array}$ & 100.80 & 100.80 & 1.37 & 1.88 & 5.62 & 98.80 & 104.42 \\
\hline Denmark & 96.42 & 98.70 & 5.22 & 27.20 & 14.87 & 88.10 & 102.97 \\
\hline Germany & 99.32 & 100.34 & 4.62 & 21.32 & 15.70 & 89.08 & 104.78 \\
\hline Estonia & 106.17 & 105.11 & 5.71 & 32.56 & 20.77 & 98.72 & 119.49 \\
\hline Ireland & 99.85 & 100.00 & 2.85 & 8.11 & 10.10 & 93.81 & 103.91 \\
\hline Greece & 102.93 & 104.10 & 1.87 & 3.51 & 5.47 & 100.00 & 105.47 \\
\hline Spain & 99.08 & 100.00 & 3.50 & 12.22 & 11.04 & 92.54 & 103.58 \\
\hline France & 97.68 & 98.32 & 4.14 & 17.14 & 14.09 & 89.26 & 103.36 \\
\hline Croatia & 97.20 & 97.78 & 1.81 & 3.27 & 5.70 & 94.30 & 100.00 \\
\hline Italy & 101.87 & 102.21 & 1.55 & 2.41 & 5.36 & 98.42 & 103.79 \\
\hline Cyprus & 102.16 & 99.50 & 6.47 & 41.84 & 20.27 & 95.35 & 115.61 \\
\hline Latvia & 100.46 & 99.16 & 3.38 & 11.42 & 12.26 & 96.10 & 108.36 \\
\hline Lithuania & 95.05 & 94.59 & 4.51 & 20.35 & 15.95 & 86.49 & 102.43 \\
\hline Luxembourg & 100.97 & 99.82 & 4.53 & 20.49 & 16.13 & 94.98 & 111.11 \\
\hline Hungary & 113.38 & 113.69 & 9.65 & 93.06 & 38.17 & 100.00 & 138.17 \\
\hline Malta & 96.45 & 96.33 & 2.29 & 5.25 & 8.04 & 91.96 & 100.00 \\
\hline Netherlands & 103.69 & 104.12 & 3.20 & 10.24 & 9.80 & 98.43 & 108.24 \\
\hline Austria & 95.53 & 96.47 & 2.83 & 8.02 & 10.60 & 89.40 & 100.00 \\
\hline Poland & 101.69 & 100.00 & 4.74 & 22.51 & 18.65 & 95.82 & 114.47 \\
\hline Portugal & 105.14 & 102.37 & 4.66 & 21.71 & 13.06 & 100.00 & 113.06 \\
\hline Romania & 104.90 & 103.43 & 4.55 & 20.73 & 14.33 & 100.00 & 114.33 \\
\hline Slovenia & 100.28 & 100.00 & 2.53 & 6.39 & 9.66 & 95.38 & 105.04 \\
\hline Slovakia & 97.33 & 96.72 & 4.72 & 22.27 & 16.99 & 91.51 & 108.49 \\
\hline Finland & 101.30 & 101.57 & 1.29 & 1.65 & 4.33 & 99.21 & 103.54 \\
\hline Sweden & 102.30 & 101.24 & 5.23 & 27.33 & 19.09 & 95.44 & 114.52 \\
\hline $\begin{array}{l}\text { United } \\
\text { Kingdom }\end{array}$ & 98.51 & 98.63 & 3.43 & 11.74 & 13.37 & 91.79 & 105.17 \\
\hline Norway & 104.78 & 101.69 & 8.27 & 68.39 & 28.39 & 95.34 & 123.73 \\
\hline Switzerland & 100.44 & 100.00 & 2.58 & 6.67 & 8.78 & 96.28 & 105.07 \\
\hline
\end{tabular}

Source: calculated by authors

Table 2

Productivity Index Descriptive Statistics

\begin{tabular}{|l|c|c|c|c|c|c|c|}
\hline Country & Mean & Median & $\begin{array}{c}\text { Standard } \\
\text { Deviation }\end{array}$ & $\begin{array}{c}\text { Sample } \\
\text { Variance }\end{array}$ & Range & Minimum & Maximum \\
\hline Belgium & 99.73 & 100.10 & 2.02 & 4.09 & 7.60 & 94.80 & 102.40 \\
\hline
\end{tabular}




\begin{tabular}{|c|c|c|c|c|c|c|c|}
\hline Bulgaria & 98.81 & 98.35 & 10.97 & 120.32 & 36.60 & 80.20 & 116.80 \\
\hline $\begin{array}{l}\text { Czech } \\
\text { Republic }\end{array}$ & 97.97 & 99.90 & 6.60 & 43.50 & 24.50 & 82.90 & 107.40 \\
\hline Denmark & 100.42 & 100.35 & 2.93 & 8.61 & 9.20 & 95.20 & 104.40 \\
\hline Germany & 100.67 & 101.55 & 2.46 & 6.03 & 7.60 & 96.40 & 104.00 \\
\hline Estonia & 98.21 & 100.50 & 7.93 & 62.95 & 27.20 & 80.00 & 107.20 \\
\hline Ireland & 102.86 & 97.10 & 14.89 & 221.62 & 48.90 & 88.90 & 137.80 \\
\hline Greece & 100.54 & 100.35 & 4.74 & 22.48 & 14.80 & 94.10 & 108.90 \\
\hline Spain & 99.30 & 99.10 & 4.37 & 19.13 & 11.60 & 94.20 & 105.80 \\
\hline France & 99.99 & 100.15 & 2.27 & 5.14 & 8.70 & 94.70 & 103.40 \\
\hline Croatia & 102.72 & 104.05 & 3.72 & 13.85 & 13.30 & 95.00 & 108.30 \\
\hline Italy & 100.07 & 100.15 & 2.08 & 4.34 & 5.20 & 97.70 & 102.90 \\
\hline Cyprus & 99.86 & 100.35 & 1.34 & 1.80 & 4.20 & 97.10 & 101.30 \\
\hline Latvia & 99.60 & 100.00 & 11.35 & 128.84 & 40.40 & 75.20 & 115.60 \\
\hline Lithuania & 98.05 & 100.50 & 12.98 & 168.53 & 40.90 & 71.90 & 112.80 \\
\hline Luxembourg & 101.65 & 101.95 & 3.05 & 9.29 & 12.00 & 96.90 & 108.90 \\
\hline Hungary & 98.49 & 99.90 & 4.19 & 17.56 & 16.00 & 86.60 & 102.60 \\
\hline Malta & 99.85 & 99.00 & 3.17 & 10.04 & 11.70 & 95.50 & 107.20 \\
\hline Netherlands & 100.22 & 100.45 & 2.58 & 6.64 & 10.70 & 94.30 & 105.00 \\
\hline Austria & 100.29 & 100.75 & 1.66 & 2.75 & 6.60 & 96.10 & 102.70 \\
\hline Poland & 98.11 & 97.00 & 10.30 & 106.09 & 31.90 & 82.30 & 114.20 \\
\hline Portugal & 97.84 & 98.60 & 3.69 & 13.61 & 11.70 & 90.30 & 102.00 \\
\hline Romania & 101.59 & 101.20 & 14.71 & 216.25 & 54.50 & 73.40 & 127.90 \\
\hline Slovenia & 99.33 & 100.60 & 5.01 & 25.11 & 18.10 & 87.40 & 105.50 \\
\hline Slovakia & 95.80 & 98.60 & 10.84 & 117.61 & 35.00 & 74.30 & 109.30 \\
\hline Finland & 99.48 & 98.95 & 2.33 & 5.41 & 9.50 & 94.60 & 104.10 \\
\hline Sweden & 98.51 & 99.50 & 4.14 & 17.13 & 16.90 & 88.70 & 105.60 \\
\hline $\begin{array}{l}\text { United } \\
\text { Kingdom }\end{array}$ & 100.85 & 101.10 & 2.10 & 4.43 & 7.40 & 96.50 & 103.90 \\
\hline Norway & 101.46 & 100.55 & 1.87 & 3.51 & 6.10 & 98.80 & 104.90 \\
\hline Switzerland & 98.22 & 99.05 & 2.11 & 4.47 & 7.70 & 92.50 & 100.20 \\
\hline
\end{tabular}

Source: calculated by authors 